\title{
Whites Science
}

A Scientific Erudition

\section{THE HOX NETWORK LEADS THE NEOPLASTIC TRANSFORMATION IN THE HUMAN SOLID TUMORS}

\author{
Procino A. \\ University of Naples Medical School "Federico II", Department of Department of Neurosciences, \\ Reproductive and Odontostomatologic Sciences. Via Pansini 5 zip code 80131 Naples Italy
}

\begin{abstract}
Class I homeobox genes (HOX), are 39 transcription factors involved in the regulation of different cell processes: i) cell identity; ii) cell growth and proliferation; iii) cell communication; iv) determining anteroposterior axis during embryonic development; these genes are characterized by 183 nucleotide sequence (homeobox) encoding for a 61 amino acid domain (hoemodomain).

HOX network controls the cell memory program during cell differentiation and is related to neoplastic transformation. Three gene families regulate the cell memory program: the Polycomb genes, able to block DNA-chromatin interaction leading to HOX genes silencing; the Trithorax genes, able to induce an open configuration of DNA-chromatin interaction and leading to HOX genes activation. Finally the HOX genes involved in the orchestration of the cell phenotype through the fine regulation of specific gene program.
\end{abstract}

The proposal of this review, considering the recent literature and my personal research, is clarify the involvement Class I homeobox genes in the control of neoplastic transformation.

Key Words : HOX, Cancer, Cell Memory Program, Solid Tumors

\section{INTRODUCTION}

Class I homeobox genes (HOX), are 39 transcription factors, mainly involved in the regulation of embryonic development program; The HOX genes are characterized by a sequence of 183 nucleotides encoding a hoemodomain of 61 aminoacid that binds to DNA, as biological gripper (Fig.1), activating or repressing specific genes [1,2]. Moreover, this network is organized in four chromosomal clusters or loci (HOXA chr 7p15.3, HOXB chr 17q21.3, HOXC chr 12q13.3 and HOXD chr 2q31), each having 9-11 genes. Based on position within the locus and similarity of homeobox sequence, corresponding genes of the four clusters, can be aligned with each other in 13 paralogous groups (Fig. 2) [3]. The HOX network is active in adult human tissues and organs, controls the spatial-temporal generation of biological structure expected during embryonic development and regulates the cell memory program. Genes related to the cell memory program, finely control the cell phenotype. Epigenetic change in the cell

\footnotetext{
*Corresponding author:

Email: alfredo.procino@unina.it
}

http://dx.doi.org/10.20530/IJIBCS 9 8-13

ISSN 2047-9093 @ 2016 memory program is critical in the onset and evolution cancer [4]. Three genes families control the cell memory program: Polycomb, able to block the interaction DNA-chromatin leading to silencing of HOX genes. Trithorax genes, able to induce the mRNA transcription through an open configuration of DNA-chromatin interaction and leads to activation of HOX genes. Finally, the HOX genes involved in the control of the phenotype through a specific gene program, mainly by means of the accurate regulation of the mRNA transcription (Fig. 3) [5].

\section{miRNAs, ncRNAs and HOX genes}

In the last decade, it has been identified 231 IncRNA able to interact with HOX genes; in details, six encoding miRNAs have been identified within the HOX network. Three genes are located between the HOX paralogous groups 9-10 and encoding miRNAs 196 (mir-196b, mir-196a-1 and mir-196a-2), two genes encoding for mir-RNAs 10a and $10 \mathrm{~b}$ between the paralogous group HOX 4-5 and finally the mir-PGCEM1 close to 5 ' end of HOXD13. Therefore, the mir-196 and mir-10 show an overlapping with paralogous group HOX 9-10 and HOX 4-5 [6]. It has been demonstrated the role of miRNA-196, in several neoplastic transformation such as gastric and colorectal 
cancer [7]. Different IncRNAs are implicated in the epigenetic control of DNA-chromatin interaction. One of the most important functions is given by the silencing of the $X$ chromosome due to ncRNA $X I S T$ through interaction with Polycomb genes products [8]. The IncRNA HOX antisense intergenic RNA (HOTAIR) was identified in 2007. HOTAIR is transcribed from HOXC locus located at chromosome 12q13.13, in intergenic and antisense position to the flanking HOXC11 and HOXC12 genes $[9,10,11,12]$. HOTAIR is the first IncRNA that control the gene expression with Trans mechanism. In details, it is able to block the transcriptional control of the HOXD locus on the chromosome-2, including the unique Polycomb Responsive Element (PRE) to date identified in the genome. Recently, 30 genes were identified into the small bowel able to control the epithelial cell differentiation and celiac disease pathogenesis [13]. Several studies suggest that HOTAIR acts regulating epigenetic states by recruiting chromatin-modifying complexes to specific target sequences that ultimately leads to suppression of several genes [14] and also HOTAIR is a powerful predictor of poor prognosis in colon cancer, mostly controlling the EMT processes [15]. In conclusion, based on the literature, the IncRNA HOTAIR and HOX genes can be considered key factors in the alteration of the epithelial cell memory program. Close the $3^{\prime}$ end of the locus HOX A, between HOX $A 1$ and HOXA2, has been identified another IncRNA called HOX antisense intergenic RNA myeloid 1 (HOTAIRM1). The IncRNA HOTAIRM1 modulates the gene expression of HOXA locus, during myelopoiesis; ncRNA can suppress distant domains interacting with specific chromosomes areas [15]. Recently, it has been identified a IncRNA, HOXA transcript at the distal tip (HOTTIP),

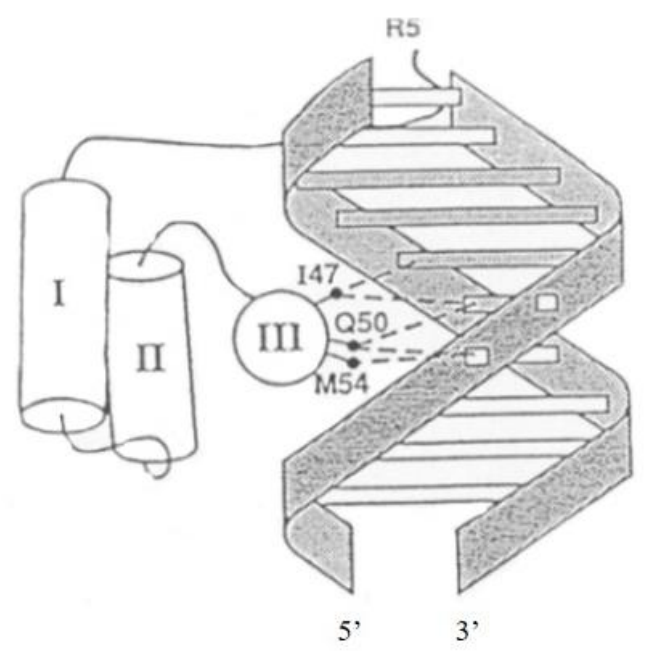

Fig. 1 : Alpha-helix homeodomain structure (see the text) transcribed from the $5^{\prime}$ end of the HOXA locus that coordinates the activation of several 5' HOXA genes in vivo [16]. HOTTIP is expressed by the development to adulthood in lumbo-sacral anatomical locations. Depletion of HOTTIP in mice induces defects resembling HOXA11 and HOXA13 inactivation, suggesting the in vivo control of lumbosacral HOX genes by HOTTIP $[16,17]$. Finally, the molecular interactions described inside the network, support the concept of the molecular software able to regulate cell identity and cell-cell communication [15] (Fig. 4). Therefore, ncRNAs are able to act on chromosomal domains and control the expression of genes far from each other. In conclusion, IncRNA play a crucial role in the achievement of processes such as development, diseases and regenerative medicine mainly by means of smart regulation of gene expression.

\section{HOX genes in human disease}

Several studies have demonstrated the involvement of homeobox genes and HOX genes in many human diseases, from cancer to pathophysiological processes against human organs (diabetes). A mutation in the HOXD13 sequence, leads to synpolydactyly, a rare hereditary disease characterized by supernumerary fingers and webbed hands. The mutation, results in the synthesis of the corresponding homeoprotein with the expansion of alanine at the amino-terminal domain [18]. Moreover, deregulation of HOXA13 gene, a gene belonging to HOX13 paralogous group, provokes a syndrome that determines malformation in the hands, foot, uro-genital structure and goes under the name of "hand-foot-genital syndrome" (HFG) [19]. These mutations confirm the crucial role of HOX genes in determining of the body structures and control of the cell growth [20]. Mutations and/or deregulation of HOX genes, have been described in several structural congenital alterations and associated with different human diseases including oncogenesis [21]. The normal development and neoplastic transformation are characterized by similar biological events concerning cell growth, cell proliferation, cell differentiation, cell communication and apoptotic pathway. Changes in specific steps of these processes, due to deregulation of genes usually implicated in the control of cell division and cell migration during embryonic development, leads to the acquisition of cancer cells phenotypes. Besides, it has already been shown the link, between embryonic development and cancer [22]. Several differences in the HOX genes expression exist between normal and neoplastic tissue, but is 


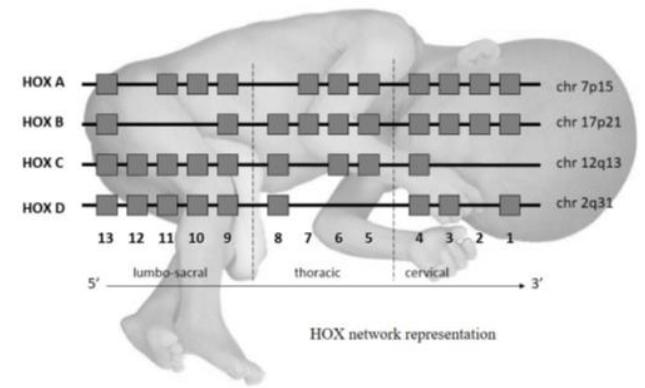

Fig. 2

not completely understood the functional relationship with the cancer phenotype. The HOX genes expression and malignant transformation, has been studied based on the hypothesis that HOX genes, expressed during embryonal development, can be re-expressed in neoplastic tissue. Therefore, homeobox genes appear to regulate normal development and normal and abnormal cell proliferation [23]. The role of HOX network in the human leukemia, and other neoplasia, is currently studied. Deregulation of HOX genes leads to different form of leukemia: myeloid leukemia (AML) and acute lymphoid leukemia (ALL). Homeobox genes are able to induce translocation and fusion in hematologic neoplasia. The translocation of $t(7 ; 11)(p 15, p 15)$ in acute myeloid leukemia, is determined by a fusion of HOXA9 protein with amino terminus region NUP98. The HOXA locus is always expressed in T-cells acute lymphocytic leukemias; moreover, HOXA cluster is up-regulated in mixed-lineage leukemia (MLL), suggesting that HOXA locus is highly involved in these leukemias, whereas HOXA9, HOXA10, HOXB3, HOXB6 and HOX B8, are able to induce leukemia latency. Furthermore, the co-upregulation of genes plays a crucial role in the progression of leukaemia; Meis homeobox-1 (MEIS-1) is an interactor of many HOX genes, mainly with HOXB4 and HOXA9, inducing Myeloid leukemia. Finally, alteration of HOX gene network is crucial in several leukemic pathologies [21].

The influence of sex hormones on the HOX genes expression, play a key role in the mammary gland and ovarian cancer; the mammary gland development, during pregnancy, is under control of HOXA9, HOXB9, HOXD9 [24]. On the other hand, high concentrations of steroid hormones during pregnancy are able to downregulate HOXC6 gene expression [25]; while, the HOXA10 and HOXA11 genes expression increase during the menstrual time, owing to high concentrations of estrogen and progesterone hormones, suggesting the involvement of these genes in endometrial development, implantation and maintenance of pregnancy [26].

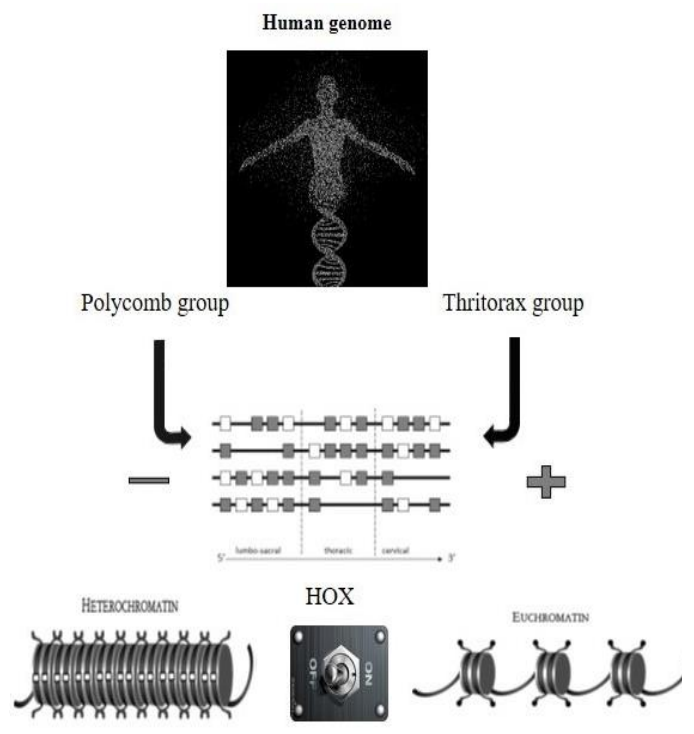

Fig. 3 : Cell Memory Program (see the text)

Recent evidences, confirms the HOXD9 upregulation in the synovial membrane of the rheumatoid arthritis (RA) patients, but not in osteoarthritis or healthy individuals, suggesting that HOXD9 protein is involved in the development of this disease [27]. In conclusion, the homeobox genes and particularly HOX network, controls normal embryonic development, cell differentiation and other crucial processes in the life of the eukaryotic cell [4]. Moreover, deregulation of HOX network is related to several disease as: congenital abnormalities [19], somatic [28], metastatic and neoplastic $[15,29,30,31]$.

\section{HOX genes in solid tumors}

Breast

The HOX network takes part in different way to the breast oncogenesis, it has been demonstrated the aberrant expression of the HOX genes: i) HOXA, HOXA6 and HOXA13; ii) HOXB, HOXB2, HOXB4, HOXB5, HOXB6, HOXB7, НOXB8, НOXB9; iii) HOXC, HOXC5, HOXC9, HOXC13; iiii) HOXD, HOXD1 and HOXD8 in breast neoplastic tissues $[32,33]$.

\section{Ovarian}

The HOXA7, HOXA9, HOXA10 and HOXA11 control the embryonic development of Müller duct and are silent in ovarian surface epithelium (OSE), but are always up-regulated in the epithelial ovarian cancer (EOC) $[34,35,36]$.

\section{Prostate}

The HOXC locus is deregulated during prostate cancer evolution. The HOXC4, HOXC5, HOXC6 and HOXC8 genes are constantly up-regulated in 


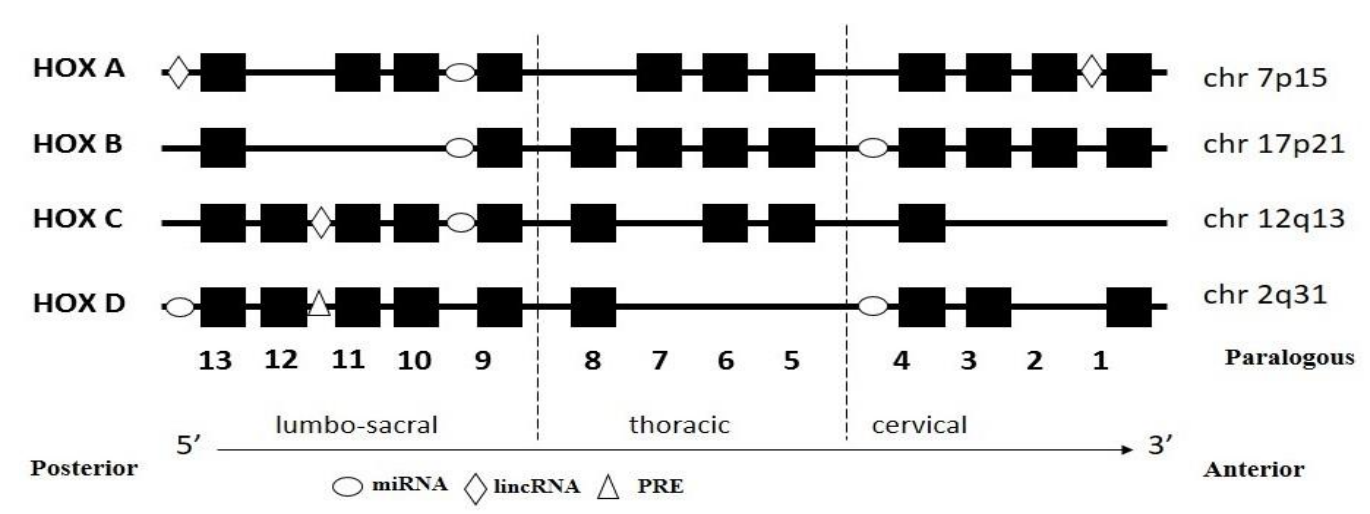

Fig. 4 : Position of miRNA and mcRNA inside network (see the text).

prostate cancer tissue, cancer cell lines and in lymph-node metastases [37].

Lung

The genes located on HOXA, HOXC and HOXD loci (HOXA1, HOXA5, HOXA10, HOXC4, HOXC6, HOXC8, HOXC9, HOXC13, HOXD8, and HOXD10), are deregulated during neoplastic transformation process [38].

Colon

The HOX13 paralogous group is involved in colon cancer: i) HOXA13 and HOXD13 upregulated in normal but silent in the tumor tissue. ii) HOXB13 and HOXC13 genes, silent in normal tissue, but constitutively expressed in malignant neoplastic disease [32]. Furthermore, HOXA9, HOXB9, HOXB3 and HOXB8 genes are overexpressed in tumor tissue compared to the controls, unlike HOXD3, HOXD4, HOXD8 and HOXD12 are downregulated in colon cancer tissue [30].

Liver

HOXA13 and IncRNA HOTTIP genes, are crucial in hepatocarcinoma (HCC) and tumor progression. In HCC, up-regulation of HOTTIP is coupled with increased of HOXA13. Conversely, low concentration of HOTTIP is coupled with low levels of HOXA13 [40].

\section{CONCLUSION}

Based on the considerations made in this manuscript, as result of the scientific literature revision and my own experience, it is clear that aberrant expression of one or more members of the HOX network, characterizes different malignancies also based on the type of tissue and the location of tumor. We have seen that there are systematic differences of HOX genes expression in tumor tissue compared to the controls. Another key factor in the study of HOX genes and human neoplasia, it refers to the degree of gene expression; we have always observed a different activity of the network in tumor tissue compared to normal tissue. Indeed, HOXC4, HOXC9, HOXC11 and HOXC13 genes are predominantly upregulated in all cancers tissue described here, with the exception of the ovarian cancer; while the HOXA9 and HOXB13 genes are identified as the most commonly altered elements described in the human tumors.

In general, the HOXA locus is often reported as typical of breast and ovarian cancer, the genes of the locus HOXB would mainly be involved in colon cancers, the genes of the locus HOXC are characteristic of the prostate and lung cancer, finally, HOXD locus is mainly related to colon and breast tumor.

Particularly interesting is the role of HOX genes locate in the posterior region of the network, HOXA9-13, HOXB9, HOXB13, HOXC9-13, HOXD913 , are often up-regulated in the solid tumors previously described. Moreover, the colon, prostate and lung tumor tissues that share a common endodermal embryonic origin tend to share the same pattern of HOXA and HOXB gene expression compared to the breast tumor tissue whose origin is ectodermal. This suggests the tumors that affect tissues with the same embryonic origin share similarities in the pattern of HOX gene expression.

Therefore, the aberrant activity of the HOX network becomes crucial during tumor evolution. The exchange rate of the HOX genes expression during neoplastic transformation, is likely due to: i) type of cancer, ii) stage of the cancer and, in some cases iii) anatomical position. The information about the role of the network in the neoplastic transformation, allows us to consider the Class I homeobox genes both crucial as bio target for future anti-cancer therapies, in the development of the human tumors. If the HOX genes are responsible of the malignancies, then further 
research should be directed to the development of therapeutic strategies able to acting in the network and control the HOX genes expression. On the other hand if the aberrant expression of the network is a consequence of carcinogenicity, then the HOX genes will have to be considered as specific biomarkers during the initial stages of neoplastic development and studied according to their sensitivity to anti-cancer therapies. Based on these assumptions, in the future we will be analyzing new results that will be crucial for the study of human tumors evolution.

\section{LIST OF ABBREVIATONS}

HOX: Class I homeobos genes

IncRNA: long non-coding RNA

miRNA: micro-RNA

PRE: Polycomb Responsive Element

AML: Myeloid Leukemia

ALL: Acute Lymphoid Leukemia

\section{REFERENCES}

1. Ferber S, Halkin A, Cohen H, Ber I, Einav $Y$, Goldberg I, et al. Nat Med. 2000 May 1;6(5):568-72. Available from: http://dx.doi.org/10.1038/75050.

2. Foucher I, Volovitch $M$, Frain $M$, Kim JJ, Souberbielle JC, Gan L, Unterman TG, Prochiantz A, Trembleau A. Hoxa5 overexpression correlates with IGFBP1 upregulation and postnatal dwarfism: evidence for an interaction between Hoxa5 and Forkhead box transcription factors. Development 2002 Sep;129(17):4065-4074.

3. Barnes TM, Kohara Y, Coulson A, Hekimi S. Meiotic recombination, noncoding DNA and genomic organization in Caenorhabditis elegans. Genetics 1995 Sep;141(1): 159-179.

4. Bantignies F, Cavalli G. Cellular memory and dynamic regulation of polycomb group proteins. Current Opinion in Cell Biology. 2006 Jun;18(3):275-83. Available from: http://dx.doi.org/10.1016/j.ceb.2006.04.003.

5. Gehring WJ, Hiromi Y. Homeotic Genes and the Homeobox. Annual Review of Genetics. 1986 Dec;20(1):147-73. Available from: http://dx.doi.org/10.1146/annurev.ge.20.120186.0 01051.

6. Alfredo P. The Paralogous Group HOX 13 Discriminates between Normal Colon Tissue and Colon Cancer. J Mol Genet Med. 2014;08(03). Available from: http://dx.doi.org/10.4172/17470862.1000130

7. Yekta S, Tabin CJ, Bartel DP. MicroRNAs in the Hox network: an apparent link to posterior prevalence. Nature Reviews Genetics. 2008 Oct;9(10):789-96. Available from: http://dx.doi.org/10.1038/nrg2400.

8. Wutz A. Xist function: bridging chromatin and stem cells. Trends in Genetics. 2007 Sep;23(9):457-64.
Available

from:

http://dx.doi.org/10.1016/j.tig.2007.07.004.

9. Rinn JL, Kertesz $M$, Wang JK, Squazzo $S L, X u X$, Brugmann SA, et al. Functional Demarcation of Active and Silent Chromatin Domains in Human HOX Loci by Noncoding RNAs. Cell. 2007 Jun;129(7):1311-23. Available from: http://dx.doi.org/10.1016/j.cell.2007.05.022.

10. Kogo R, Shimamura T, Mimori K, Kawahara K, Imoto $S$, Sudo $T$, et al. Long Noncoding RNA HOTAIR Regulates Polycomb-Dependent Chromatin Modification and Is Associated with Poor Prognosis in Colorectal Cancers. Cancer Research. 2011 Aug 23;71(20):6320-6. Available from: http://dx.doi.org/10.1158/0008-5472.can-11-1021.

11. Long non-coding RNAs in cancer progression. Tano, K.; Akimitsu, N. 2012 Front. Genet. 3, 219.

12. He $S$, Liu $S$, Zhu $H$. The sequence, structure and evolutionary features of HOTAIR in mammals. BMC Evolutionary Biology. 2011;11(1):102. Available from: http://dx.doi.org/10.1186/1471-2148-11102.

13. Juuti-Uusitalo K, Mäki M, Kainulainen $H$, Isola J, Kaukinen K. Gluten affects epithelial differentiation-associated genes in small intestinal mucosa of coeliac patients. Clinical \& Experimental Immunology. 2007 Sep 21;150(2):294-305. Available from: http://dx.doi.org/10.1111/j.13652249.2007.03500.x

14. Pádua Alves $C$, Fonseca AS, Muys BR, de Barros e Lima Bueno R, Bürger MC, de Souza JES, et al. Brief Report: The lincRNA Hotair is Required for Epithelial-to-Mesenchymal Transition and Stemness Maintenance of Cancer Cell Lines. Stem Cells. 2013 Dec;31(12):2827-32. Available from: http://dx.doi.org/10.1002/stem.1547.

15. Wu ZH, Wang XL, Tang HM, Jiang $T$, Chen J, Lu S, Qiu GQ, Peng ZH, Yan DW. Long non-coding RNA HOTAIR is a powerful predictor of metastasis and poor prognosis and is associated with epithelialmesenchymal transition in colon cancer. Oncol Rep. 2014 Jul;32(1):395-402

16. Wang KC, Yang YW, Liu B, Sanyal A, CorcesZimmerman $\mathrm{R}$, Chen $\mathrm{Y}$, et al. A long noncoding RNA maintains active chromatin to coordinate homeotic gene expression. Nature. 2011 Mar 20;472(7341):120-4. Available from: http://dx.doi.org/10.1038/nature09819.

17. Chirgwin JM, Przybyla AE, MacDonald RJ, Rutter WJ. Isolation of biologically active ribonucleic acid from sources enriched in ribonuclease. Biochemistry. 1979 Nov;18(24):5294-9. Available from: http://dx.doi.org/10.1021/bi00591a005.

18. Muragaki $Y$, Mundlos S, Upton J, Olsen BR. Altered Growth and Branching Patterns in Synpolydactyly Caused by Mutations in HOXD13. Science. 1996 Apr 26;272(5261):548-51. Available from: http://dx.doi.org/10.1126/science.272.5261.548 
19. Mortlock DP, Innis JW. Mutation of HOXA13 in hand-foot-genital syndrome. Nat Genet. 1997 Feb;15(2):179-80. Available from: http://dx.doi.org/10.1038/ng0297-179.

20. Scott MP. Hoxgenes, Arms and the Man. Nat Genet. 1997 Feb;15(2):117-8. Available from: http://dx.doi.org/10.1038/ng0297-117

21. Procino A. HOX genes and oncogenesis. J Mol Gen Med. 2013 Oct. 15;8(3):1-6 Available from: http://dx.doi.org/10.4172/1747-0862.1000130

22. Caldas C, Aparicio S. Cell Memory and cancer - the history of the trithorax and Polycomb group genes. Cancer Metastasis Rev. 1999;18:313-29.

23. Grier D, Thompson A, Kwasniewska A, McGonigle G, Halliday H, Lappin T. The pathophysiology of HOX genes and their role in cancer. The Journal of Pathology. 2005 Jan;205(2):154-71. Available from: http://dx.doi.org/10.1002/path.1710.

24. Chen F, Capecchi MR. Paralogous mouse Hox genes, Hoxa9, Hoxb9, and Hoxd9, function together to control development of the mammary gland in response to pregnancy. Proceedings of the National Academy of Sciences [Internet]. Proceedings of the National Academy of Sciences; 1999 Jan 19;96(2):541-6. Available from: http://dx.doi.org/10.1073/pnas.96.2.541.

25. Garcia-Gasca A, Spyropoulos DD. Differential mammary morphogenesis along the anteroposterior axis in Hoxc6 gene targeted mice. Dev Dyn. 2000 Oct;219(2):261-76.

26. Daftary GS, Taylor HS. Implantation in the Human: The Role of HOX Genes. Semin Reprod Med. 2000;18(03):311-20.

27. Nguyen $N C$, Hirose $T$, Nakazawa $M$, Kobata $T$, Nakamura H, Nishioka K, Nakajima T. Expression of HOXD9 in fibroblast-like synoviocytes from rheumatoid arthritis patients. Int J Mol Med. 2002 Jul;10(1):41-8.

28. Nakamura $T$, Largaespada DA, Lee MP, Johnson LA, Ohyashiki K, Toyama K, et al. Fusion of the nucleoporin gene NUP98 to HOXA9 by the chromosome translocation $t(7 ; 11)(\mathrm{p} 15 ; \mathrm{p} 15)$ in human myeloid leukaemia. Nat Genet. 1996 Feb;12(2):154-8. Available from: http://dx.doi.org/10.1038/ng0296-154

29. Sukumar S, Raman V, Martensen SA, Reisman D, Evron E, Odenwald WF, et al. Nature. 2000 Jun 22;405(6789):974-8. Available from: http://dx.doi.org/10.1038/35016125.

30. Cillo C, Schiavo G, Cantile M, Bihl MP, Sorrentino P, Carafa V, et al. The HOX gene network in hepatocellular carcinoma. Int J Cancer. 2011 May 30;129(11):2577-87. Available from: http://dx.doi.org/10.1002/ijc.25941.
31. Bhatlekar S, Fields JZ, Boman BM. HOX genes and their role in the development of human cancers. J Mol Med. 2014 Jul 5;92(8):811-23. Available from: http://dx.doi.org/10.1007/s00109-014-1181-y

32. Cantile M, Pettinato G, Procino A, Feliciello I, Cindolo $L$, Cillo $C$. In vivo expression of the whole HOX gene network in human breast cancer. European Journal of Cancer. 2003 Jan;39(2):257$64 . \quad$ Available from: http://dx.doi.org/10.1016/s0959-8049(02)00599-3

33. Hur H, Lee J-Y, Yun HJ, Park BW, Kim MH. Analysis of HOX Gene Expression Patterns in Human Breast Cancer. Mol Biotechnol. 2013 Jul 3;56(1):64-71. Available from: http://dx.doi.org/10.1007/s12033013-9682-4

34. Gendronneau G, Boucherat O, Aubin J, Lemieux M, Jeannotte L. The Loss of Hoxa5 Function Causes Estrous Acyclicity and Ovarian Epithelial Inclusion Cysts . Endocrinology. 2012 Mar;153(3):1484-97. Available from: http://dx.doi.org/10.1210/en.20111766

35. Cheng W, Liu J, Yoshida H, Rosen D, Naora H. Lineage infidelity of epithelial ovarian cancers is controlled by HOX genes that specify regional identity in the reproductive tract. Nat Med. 2005 Apr 10;11(5):531-7. Available from: http://dx.doi.org/10.1038/nm1230

36. Naora H, Montz FJ, Chai C-Y, Roden RBS. Aberrant expression of homeobox gene HOXA7 is associated with mullerian-like differentiation of epithelial ovarian tumors and the generation of a specific autologous antibody response. Proceedings of the National Academy of Sciences. 2001 Dec 11;98(26):15209-14.

37. Miller GJ, Miller HL, van Bokhoven A, Lambert JR, Werahera PN, Schirripa O, Lucia MS, Nordeen SK Aberrant HOXC expression accompanies the malignant phenotype in human prostate. Cancer Res. 2003 Sep 15;63(18):5879-5888

38. Omatu T Overexpression of human homeobox gene in lung cancer A549 cells results in enhanced motile and invasive properties. Hokkaido Igaky Zasshi. 1999 Sep 74(5):367-376

39. Kanai M, Hamada J, Takada M, Asano T, Murakawa $\mathrm{K}$, Takahashi $\mathrm{Y}$, Murai T, Tada M, Miyamoto $\mathrm{M}$, Kondo S, Moriuchi T. Aberrant expressions of HOX genes in colorectal and hepatocellular carcinomas. Oncol Rep. 2010 Mar 23(3):843-851

40. Quagliata L, Matthias S.M, Piscuoglio S, Arabi L, Ruiz C, Procino A, Kovac M, Moretti F, Makowska S, Boldanova T, Anderson J.B, Hammerle M, Tornillo L, Heim M.H, Diederichs S, Cillo $C$ and Terracciano L. InCRNA HOTTIP/HOXA13 expression is associated with disease progression and predicts outcome in hepatocellular carcinoma patients. Hepatology. 2014 Mar;59(3):911-923. 